\title{
Pessary use in pregnant women with short cervix
}

\author{
Tuncay Yüce, Bahar Konuralp, Erkan Kalafat, Feride Söylemez \\ Department of Obstetrics and Gynecology, Ankara University School of Medicine, Ankara, Turkey
}

\begin{abstract}
The purpose of this case series is to provide preliminary evidence on the efficacy of pessary application in women with short cervix and at risk for preterm labor. Between May 2015 and July 2015, four pregnant women were followed-up with Arabin pessaries. The gestational age at the time of diagnosis was between the $23^{\text {th }}$ and $29^{\text {th }}$ weeks. Pessary application was associated with a prolongation of pregnancy lasting between 28 and 98 days. The gestational age at the time of delivery was between the 33rd and 39th weeks. Pessary use is non-invasive for the prolongation of pregnancy in pregnant women with shortened cervix. The major advantage of pessary use is its easy application without requiring anesthesia. (J Turk Ger Gynecol Assoc 2016; 17: 120-2)
\end{abstract}

Keywords: Cervical pessary, preterm birth, short cervix

Received: 25 May, 2015 Accepted: 28 December, 2015

\section{Introduction}

Preterm labor and birth, i.e., birth before the $37^{\text {th }}$ week of gestation, is a major cause of perinatal morbidity and mortality in the developed world (1). Shortening cervical length is identified as a risk factor for preterm birth. Transvaginal measurements of cervix that reveals shortening (below $25 \mathrm{~mm}$ ) or cervical funneling sign is an important indicator of threatened preterm birth. The management of such cases usually consists of progesterone administration or cervical cerclage with progesterone (2). However, conclusive evidence on the effectiveness of these treatments is lacking. Cervical pessary is a non-invasive alternative to cervical cerclage and it has the advantage of not requiring anesthesia (3). In the late 1970s, Hans Arabin in Germany designed a silicon pessary applied to the cervix and that works by changing the uterocervical angle and displacing it more posteriorly (Cerclage Pessary, Dr. Arabin GmbH and Co. KG; Witten, Germany). Compared with other pessaries, Arabin's pessary is flexible and more easily applied to the cervix (4).

\section{Case Series}

In Ankara University, Department of Obstetrics and Gynecology, between 2007 and 2014, we treated 136 patients for shortened cervix and threatened premature labor with mechanical and invasive methods. In total, 132 of these patients were treated with cervical cerclage and four with cervical pessary. Patients who did not accept cervical cerclage and cervical pessary were treated with medication and bed rest. Pessary application was restricted to patients who did not accept cervical cerclage treatment. We present the cases of the four patients with cervical pessary application for the prevention of preterm birth. The patients had no history of prior preterm birth, and progesterone treatments were withheld. Cervical and vaginal swabs were taken from all patients, and cultures were reported to have normal flora. Written consents were taken prior to treatment. There were no complications related to pessary application, and the patients were not administered tocolytics, progesterone, and antibiotics during pregnancy.

\section{Case 1}

A 23-year-old primigravida woman was referred to our clinic for cervical insufficiency. The woman was at her $29^{\text {th }}$ week of gestation, and the amniotic membrane protruded into vaginal vault. Her digital examination showed a cervical dilatation of $3 \mathrm{~cm}$. A pessary was applied. She was re-admitted to the hospital during her $33^{\text {rd }}$ week of gestation due to uterine contractions. The cervical dilatation at the time was $6 \mathrm{~cm}$, and the pessary was removed. A $2110 \mathrm{~g}$ female baby was vaginally delivered with Apgar scores of 7 and 9. The time from pessary application to delivery was 28 days (Table 1).

\section{Case 2}

A 29-year-old, gravida 2, parity 1 woman was referred to our clinic at the $23^{\text {rd }}$ week of gestation with an initial diagnosis of cervical insufficiency. Her initial assessment revealed a shortened cervix $(14 \mathrm{~mm})$ and a closed cervical os. A cervical pessary was placed in the $23^{\text {rd }}$ week of gestation. The patient remained asymptomatic until the $33^{\text {rd }}$ week of gestation. She was readmitted at 33 weeks and 4 days due to rupture of membranes, and the pessary was removed. After pessary removal, digital examination showed a cervical dilatation of $7 \mathrm{~cm}$, and a $1610 \mathrm{~g}$ female baby was vaginally delivered with Apgar scores of 7 and 9 . The time from pessary application to delivery was 72 days (Table 1). 
Table 1. Baseline characteristics and delivery data of pessary cases

\begin{tabular}{|c|c|c|c|c|c|c|c|c|c|}
\hline Case & Age & Parity & $\begin{array}{c}\text { GA at } \\
\text { admission } \\
\text { (week, day) }\end{array}$ & $\begin{array}{c}\text { Cervical } \\
\text { assessment }\end{array}$ & $\begin{array}{l}\text { GA at pessary } \\
\text { application }\end{array}$ & $\begin{array}{c}\text { GA at pessary } \\
\text { removal }\end{array}$ & $\begin{array}{c}\text { GA at } \\
\text { delivery }\end{array}$ & $\begin{array}{c}\text { Time from } \\
\text { pessary } \\
\text { application to } \\
\text { delivery }\end{array}$ & $\begin{array}{c}\text { Birth } \\
\text { weight }\end{array}$ \\
\hline 2 & 29 & 1 & $23 \mathrm{w}, 1 \mathrm{~d}$ & Cervical length: $14 \mathrm{~mm}$ & $23 \mathrm{w}, 2 \mathrm{~d}$ & $33 \mathrm{w}, 4 \mathrm{~d}$ & $33 \mathrm{w}, 4 \mathrm{~d}$ & 72 days & $1610 \mathrm{~g}$ \\
\hline 3 & 29 & 1 & $27 \mathrm{w}, 4 \mathrm{~d}$ & $\begin{array}{l}\text { Cervical length: } \\
15 \text { mm, funneling } \\
\text { sign positive }\end{array}$ & $27 \mathrm{w}, 5 \mathrm{~d}$ & $39 \mathrm{w}, 0 \mathrm{~d}$ & $39 \mathrm{w}, 0 \mathrm{~d}$ & 76 days & $3300 \mathrm{~g}$ \\
\hline 4 & 31 & 2 & $23 \mathrm{w}, 1 \mathrm{~d}$ & $\begin{array}{c}\text { Cervical length: } \\
15 \mathrm{~mm}, \\
\text { Cervical dilatation: } \\
5 \mathrm{~cm}\end{array}$ & $23 \mathrm{w}, 3 \mathrm{~d}$ & $37 \mathrm{w}, 2 \mathrm{~d}$ & $37 \mathrm{w}, 3 \mathrm{~d}$ & 98 days & $3200 \mathrm{~g}$ \\
\hline
\end{tabular}

Case 3

A 29-year-old, gravida 2, parity 0 woman was referred to our clinic for cervical insufficiency at 27 weeks and 4 days. Her initial assessment revealed a shortened cervix of $15 \mathrm{~mm}$ with a funneling sign. A cervical pessary was placed on the same day. She remained asymptomatic until term. The pessary was removed at the $39^{\text {th }}$ week of gestation due to the rupture of membranes. The cervical dilatation at admission was $5 \mathrm{~cm}$, and $3300 \mathrm{~g}$ female baby was vaginally delivered with Apgar scores of 8 and 9 . The time from pessary application to delivery was 76 days (Table 1 ).

\section{Case 4}

A 31-year-old, gravida 3, parity 2 woman was referred to our clinic for cervical insufficiency at 23 weeks and 4 days. Her initial assessment revealed a cervical dilatation of $5 \mathrm{~cm}$ and transvaginal measured cervical length of $15 \mathrm{~mm}$. A cervical pessary was placed at 23 weeks and 4 days. She remained symptom free until the $37^{\text {th }}$ week of gestation. She was readmitted at 37 weeks and 3 days due to uterine contractions. The digital examination of her cervix revealed an unchanged dilatation of $5 \mathrm{~cm}$, and the pessary was removed due to regular uterine contraction and also as the patient reached term. A $3200 \mathrm{~g}$ female baby was vaginally delivered with Apgar scores 8 and 9 . The time from pessary application to delivery was 98 days (Table 1 ).

\section{Discussion}

Preterm birth is a major cause of neonatal mortality and morbidity in developed countries. It is implicated as a cause of both short- and long-term morbidity in infants (1), and the prevention of preterm birth is the most effective way of decreasing morbidity rates. Shortened cervical length is an important predictor of spontaneous preterm birth, and several treatment strategies have been proposed. Alfirevic et al. (5) reported that cervical cerclage, vaginal progesterone, and cervical pessary appear to have a similar effectiveness as management strategies in women with singleton pregnancy, previous spontaneous preterm birth, and short cervix. Cervical cerclage is the most common mechanical prevention method for the prevention of preterm birth. However, the procedure is not without complica- tions (6). Cervical pessaries have been shown to be efficacious in preventing preterm birth, especially in a high-risk population of women with a shortened cervical length (7-10). On the other hand, a randomized controlled trial showed that the prophylactic use of cerclage pessaries did not reduce the rate of preterm delivery before 34 weeks (11). Cervical pessary is an inexpensive and less invasive option to cervical cerclage. Pessary application and removal do not require anesthesia. Pessary use, instead of cervical suturing, can decrease hospital stays and reduce healthcare costs. In low-resource countries, cervical pessaries are an alternative method for the prevention of preterm birth. Few complications arising from pessary use have been reported, including increased vaginal discharge. However no major infectious morbidity, i.e., chorioamnionitis, has been reported. It appears to be cost effective with minimal side effects, and Quaas et al. (9) recommended the Arabin pessary as a favorable alternative to surgical cerclage with either prophylactic or therapeutic intent.

Pessary use for the treatment of cervical insufficiency is uncommon. A cervical cerclage was used in almost 130 patients in our clinic during the last 10 years, while we applied a cervical pessary to only four patients for the prevention of preterm labor. A cervical pessary resulted in a modest prolongation of pregnancy in all four patients.

Although our experience is derived from four cases, cervical pessaries seem to be safe and feasible for the prevention of preterm labor. The efficacy of cervical cerclages in the prevention of preterm birth in women with short cervix is unproven. If the efficacy of pessaries in preventing preterm birth is confirmed, they may become a safe alternative to traditional surgical cerclage when surgery is undesired by the patient or doctor. In the absence of randomized cohorts, the decision regarding which treatment options to choose should take into account the preferences of patients and clinicians.

Ethics Committee Approval: N/A.

Informed Consent: Written informed consent was obtained from patients who participated in this case.

Peer-review: Externally peer-reviewed. 
Author Contributions: Concept - T.Y., B.K.; Design - T.Y., B.K.; Supervision - T.Y., F.S.; Funding - T.Y., B.K.; Materials - T.Y., E.K.; Data Collection and/or Processing - T.Y., E.K.; Analysis and/or Interpretation - T.Y., B.K.; Literature Review - T.Y., B.K.; Writer - T.Y., B.K., E.K.; Critical Review - T.Y., F.S.

Conflict of Interest: No conflict of interest was declared by the authors.

Financial Disclosure: The authors declared that this study has received no financial support.

\section{References}

1. Lumley J. Defining the problem: the epidemiology of preterm birth. BJOG 2003; 110(Suppl 20): 3-7. [CrossRef]

2. Pessel C, Moni S, Zork N, Brubaker S, Vink J, Fuchs K, et al. The effect of intramusculer progesterone on the rate of cervical shortening. Am J Obstet Gynecol 2013; 209: 269.e1-7. [CrossRef]

3. Wetta LA, Biggio JR Jr. Cervical pessary use and preterm birth. Clin Obstet Gynecol 2014; 57: 607-15. [CrossRef]

4. Arabin B, Alfirevic Z. Cervical pessaries for prevention of spontaneous preterm birth: past, present, future. Ultrasound Obstet Gynecol 2013; 42: 390-9.
5. Alfirevic Z, Owen J, Carreras Moratonas E, Sharp AN, Szychowski JM, Goya M. Vaginal progesterone, cerclage or cervical pessary for preventing preterm birth in asymptomatic singleton pregnant women with a history of preterm birth and a sonographic short cervix. Ultrasound Obstet Gynecol 2013; 41: 146-51. [CrossRef]

6. Suhag A, Berghella V. Cervical cerclage. Clin Obstet Gynecol 2014; 57: 557-67. [CrossRef]

7. Goya M, Pratcorona L, Merced C, Rodó C, Valle L, Romero A, et al. Cervical pessary in pregnant women with a short cervix (PECEP): an open-label randomised controlled trial. Lancet 2012; 379: 18006. [CrossRef]

8. Abdel-Aleem H, Shaaban OM, Abdel-Aleem MA. Cervical Pessary for preventing preterm birth. Cochrane Database Syst Rev 2013; 5 : CD007873. [CrossRef]

9. Quaas L, Hillemanns HG, du Bois A, Schillinger H. The Arabin cerclage pessary an alternative to surgical cerclage. Geburtshilfe Frauenheilkd 1990; 50: 429-33. [CrossRef]

10. Arabin B, Halbesma JR, Vork F, Hübener M, van Eyck J. Is treatment with vaginal pessaries an option in patients with a sonographically detected short cervix? J Perinat Med 2003; 31: 122-33. [CrossRef]

11. Hui SY, Chor CM, Lau TK, Lao TT, Leung TY. Cerclage pessary for preventing preterm birth in women with a singleton pregnancy and a short cervix at 20 to 24 weeks: a randomized controlled trial. Am J Perinatol 2013; 30: 283-8. 